\title{
Performance Comparison of Handover mechanisms in mobile wireless communication networks for Broadband Wireless Access
}

\section{Systems}

\author{
Rebin Abdullah Saeed ${ }^{2}$. \\ ${ }^{a}$ Department of Information Technology, Lebanese French University, Erbil, Kurdistan Region, Iraq. \\ * Corresponding Author: rebin.abdullah88@gmail.com
}

Received : $26^{\mathrm{h}}$ February 2020, Accepted : $17^{\text {th }}$ April 2020

\begin{abstract}
Mobility is the mobile communication characteristics which make it diverse and attractive for all. Wireless communication is now attractive to the whole world and provides the ability of users to communicate very active. Transferring the users from one radio network to another is accomplishing the IT. The process is called the handover process. The transfer takes place by adjusting the duration of the soft transfers, the area size and either by cell crossing or by deterioration in the signal quality of the current channel - the brief overview of handover, Handover in WiMAX and LTE, types of handover, handover types solutions, approaches used in literature are typically transfer parameters and I contemporary the convergent fact for continuance in the area of mobile and wireless communication Handover.
\end{abstract}

Keywords: Wireless Communication Network, WiMAX, LTE, Handover, GSM and CDMA.

\section{Introduction}

Handover is a progression in mobile communications and telecommunications in which a connected a data session, or cellular calling shall be transferred from one cell site (base station) to another without session disconnection. Cellular services are based on handover and mobility, permitting the user to be progressed from one cell position range to another or to be moved to the nearest cell position for better action [1,2,3]. Handover is an essential element in deploying and planning cellular networks. It lets users create connect phone or data sessions calls on the move. This process keeps connected the calls and data sessions even if users move from one cell position to another. Mobility is the main features that has made cellular wireless communication an indispensable device. Handover is obligatory during signal quality deprivation or/and cellcrossing in the current channel. And also, we need handover for user performance and mobility. During the transition, users and networks are transferred to another network or base station [4]. The fundamental of $5 \mathrm{G}$ is heterogeneous networks, and smooth handover is permanent in such 
networks. Handover phases are, decision, execution and: discovery. Network discovery helps to find a suitable network that satisfies the user on desired Quality of Services (QoS). Decision phase is where the handover should take place (handover initiation phase). These phases helps to regulate seamlessness handover. Wrong initiation time will lead to increased unnecessary handover or call drop rate resulting in poor QoS. Therefore, in order to ensure that QoS will not be affected and unnecessary transfers are avoided, handover take place at right time by the decision to trigger the handover taking due account of all the parameters.

\section{Classification of Handover}

\subsection{Technology Assessment}

\subsubsection{Horizontal Handover}

A horizontal handover is a traditional handover. Horizontal handovers are Layer-2 handovers. Only BS is changed here that maintains the IP information. Here, MS uses the hard handover (HHO, break-before-make handover) when the information is moved to another BS. Where connections are broken at every layers and no context information is shared between BSs. Latency is on the order of around 1000ms. Recent WiMAX standard supports the soft handover (SHO, make-before-break) and Fast BS Switching (FBSS) [5,6,7].

\subsubsection{Vertical Handover}

There are also intertechnology handovers where the connection of a call will be transferred from one access technology to another assess technology, e.g. a call is transferred from Group Special Mobile (GSM) to the Universal Mobile Telecommunications System (UMTS) or from Code-Division Multiple Access (CDMA IS-95) to cdma2000. This is called as inter-technology handover, and it's a transition that takes place between two different technology networks, e.g. 3 G to $4 G$. [8,9].

\section{Protocol Layers}

- Cross Layer handover

- Data link Layer handover

- Network Layer handover

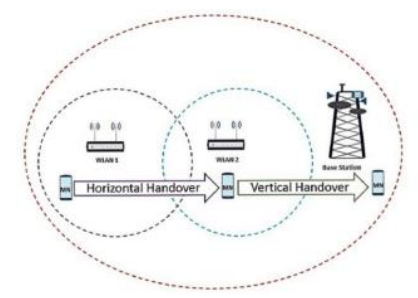

Fig. 1. Horizontal and Vertical Handover 
4. Type of Technology for Network supports

\subsection{Hard handover}

\subsubsection{Before $\mathrm{HO}$}

- Network Topology Advertisement

- MS scanning of neighbour BSs

- Association procedure

\subsubsection{During $\mathrm{HO}$}

- Cell Reselection

- HO decision and initiation

- Synchronize with the new downlink to obtain parameters

- Obtain the uplink parameters

- Adjustment of Ranging and uplink parameter

- MS re-authorization

- Re-registration

- Termination with serving BS

\subsection{Soft Handover}

Soft Handover is similar to the HHO with one significant difference; at the same time, an MS is registered with SHO on multiple BSs (the Active Set). [10,11].

\subsection{Softer Handover}

This is same as soft transfer that happens between two different sectors of the same cell.
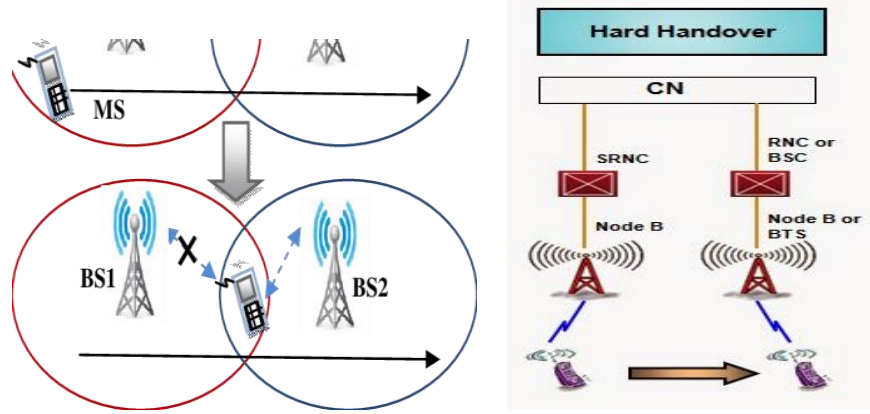

Fig.2. Hard-Handover Mechanism 


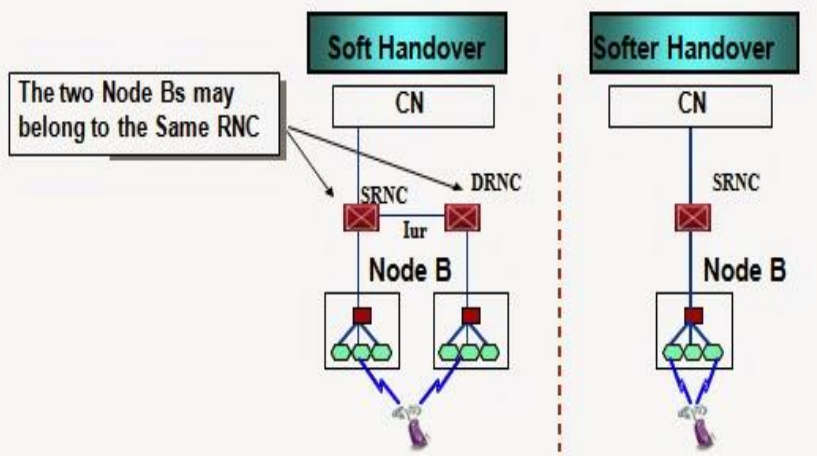

Fig.3. Soft and Softer Handover

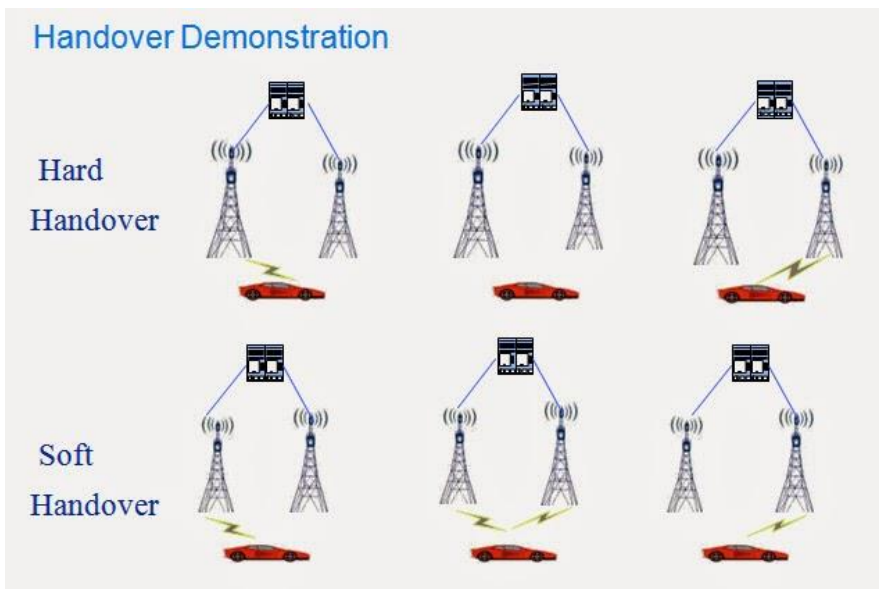

Fig.4. Hard Handover

\section{Different Handover Mechanisms in the LTE Network}

In Handover Parameter Optimization (HPO), LTE system Handover performance can be improved by (HPO). Load Balancing (LB) is an instrument that advances the user's fulfillment. LB may result in the rise of the frequency of the inter-cell handover and henceforth increase its opportunity of handover glitches leading to discount in handover performance. Also, the techniques to improve both HPO and LB do not consider the network permitted maximum radio link failure (RLF) ratio. Radio link failure would raise the possibility of call drop. The (DHA) dynamic hysteresis-adjusting method be able to be used to develop handover performance and the number of fulfilled users in LTE networks. Dynamic Hysteresis Adjusting uses the allowed extreme RLF ratio is considered as a key indicator[12].

In that respect, one of the main objectives of LTE or any wireless system is to provide seamless and rapid transfer from one cell (a source cell) to another (a target cell). During the 
handover period, the service should be maintained; data transmission would not be delayed or missed; otherwise, output would be significantly compromised.

The versatility for supporting various $4 \mathrm{G}$ implementations and meeting the latency criteria on handover is important for the design of IMT-Advanced Systems. In the cellular network mobility management, handover is one of the primary mechanisms. The IMTAdvanced systems are designed with IEEE $802.16 \mathrm{~m}$, based on next generation WiMAX networks and 3GPP LTE-Advanced. Different delivery schemes are developed, proposed and analyzed with IEEE $802.16 \mathrm{~m}$ and 3GPP to minimize the latency of delivery and to meet the quality of service requirement during delivery [13].
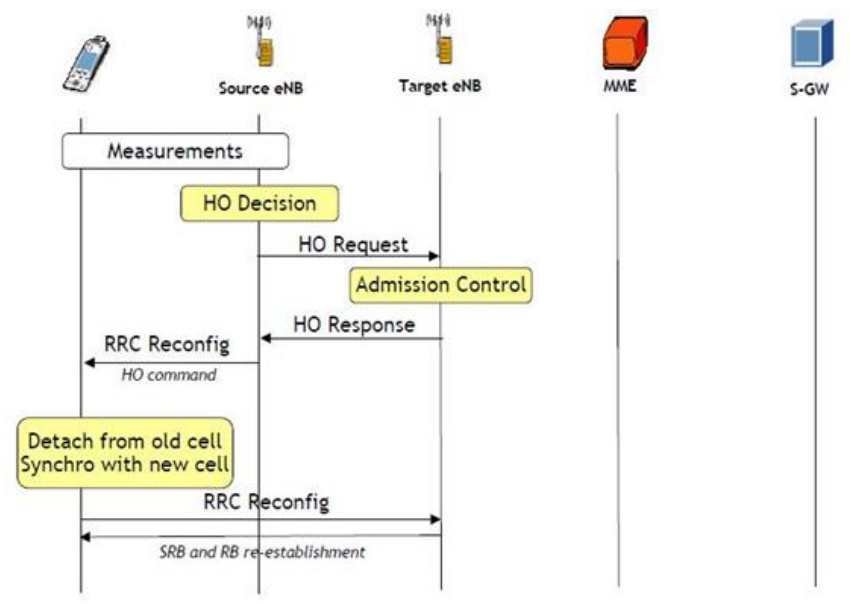

Fig.5. Handover Process in LTE

\section{Handovers in Mobile WiMAX}

A great need for a mobile device is to change its base station coverage if a mobile station (MS) is reached by another base station with the strongest signal strength. Handover is a process that provides continuous connection where a Mobile Station travels from one base station's air interface to another Base Station's (BS) air interface without troubling the existing connections. Supporting mobility requires transfers. For a transfer to take place, one must have at least two base stations: (i) base station serving (SBS) and (ii)base station target (TBS) serving. The transfers have typically measured a change in service to the base station and does not inherently mean that the BS needs to be changed [14,15].

\subsection{Latency and Handover}

Handover is a system for keeping user contact session uninterrupted during a user's travel from a place to another. When Mobile Station (MS) moves to a cell and conducts 
handover, the MS service packets are delayed, and the operation may be interrupted for a while. This delay is referred as Latency Time.

Latency time is not a problem for a non-real-time services like e-mail or file transfer. The delay prone applications like video streaming service, should however be provided within 20 to $25 \mathrm{~ms}$ delay. If the real-time packet transmission delay will be longer than the playout delay, then those packets are discarded and the probability of packet loss will be increased.

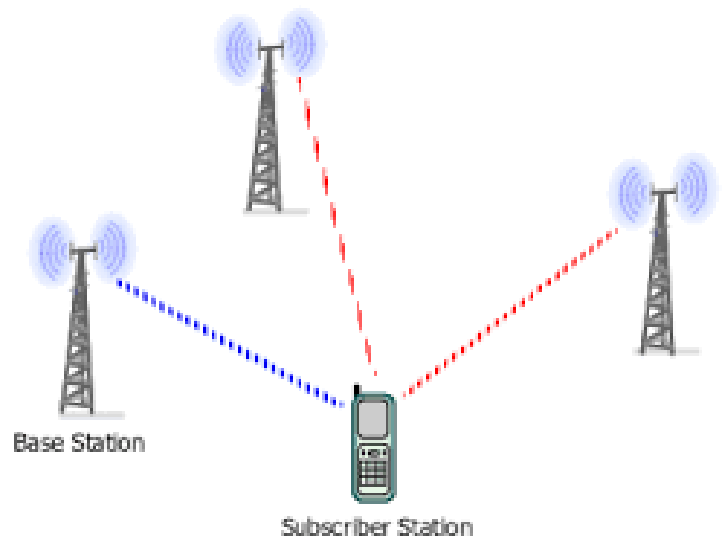

Fig.6. Handovers in Mobile WiMAX

\subsection{Handover Procedure}

The Serving BS sends information message for a handover process, usually uses MOB NBR-ADV, which has information about neighboring BSs. MS regularly checks the neighboring BSs for selecting the target BS candidates by the consistency of the signals and message is sent to the serving BS with the order for handover. The Serving BS exchanges the messages with destination BSs candidates to select a target BS and sends the message of handover response to MS. After receiving the message, the MS breaks the link to the serving BS and connects to the target BS and performs the process of re-entering the network. The Target BS receives the MS ' security information from the serving BS. Upon re-entering the network MS may receive or send traffic. The re-entry process of the network involves synchronization with the new downlink, range and synchronization for uplink, re-authorization, and re-registration. The MS synchronizes with the new downlink of Target BS after breaking the connection with Serving BS to get parameters for DL and UL transmission. MS conducts process to acquire correct offset timing and power adjustments. Target BS uses the Fast-Ranging IE for this range process and provides the MS with a non-contention range opportunity. If MS do not receive the Fast-Ranging IE message then it conducts a contention-based range process by transmitting the CDMA codes. 


\subsection{Handover Mechanisms}

HO latency remains a problem which affects applications in real time environment. Many researchers proposed methods to improve the mechanism for $\mathrm{HO}$ applications for real time application. This section gives a few suggestions for improving the HO mechanism.

\section{Fast Handover Algorithm for IEEE 802.16e Broadband Wireless Access System}

Lee introduced the IEEE 802.16e BWA quick HO algorithm for reducing the loss of wireless channel resources and latency of the HO. He suggested algorithm involves Target BS Selection (TBS), Quick Synchronization and Association (FSA), and OHIT. Here running time of $\mathrm{HO}$ is evaluated for four different scenarios of HO. This will result in increased system throughput and a certification of proposed algorithm's efficiency. Some parameters of this scheme depend on the traffic condition of the backbone network, the rate of cell charging, user mobility, and CINR.

- Type 1 - contention based ranging with pre-association.

- Type 2 - contention based ranging without pre-association.

- Type 3 - non-contention based ranging with pre-association.

- Type 4 - non-contention based ranging without pre-association.

\section{Fast Base Station Switching in Soft Handover}

A switching technique is considered to quick base station. In this process, a collection of diversity for each mobile station is preserved. Diversity set is maintained by mobile station as well as base station service. In fig. 7, a mobile station selects a base station from diversity set which is a collection of base stations that is chosen as target base station for handover. Diversity set is considered as the presenter base station which sends its current location to the controller of the base station for a handover decision.

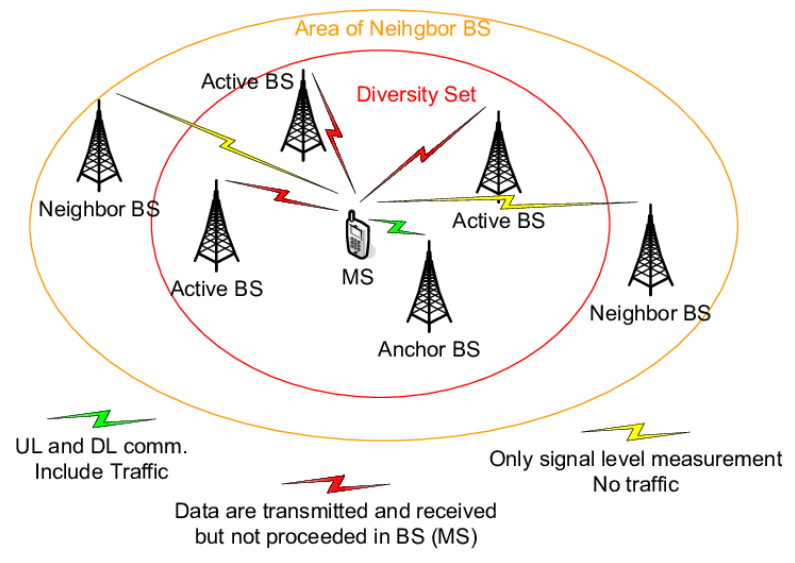

Fig.7. Fast Base Station Switching 
The base and mobile station serving monitor the nearby base stations which is added in a diversity set. Whenever there is a need for the base station controller to hand over to the mobile station the initiation message is sent. Depending on the implementation, the decision on the transfer is taken by the mobile station, base station or base station controller.

\section{General Procedure of Handover Control}

- Measuring

- Remote Network Support (RNC) determines the measurement artifacts. Normally either the P-CPICH channel's Ec / Io or RSCP (Received Signal Code Power) is used for the decision on handover.

- RNC takes the measurement of Ec / Io (Energy per chip to interference power ratio) because $\mathbf{E c}$ / Io embodies the signal strength received and the interference. The Ec / Io and RSCP relation is follows:

- $\mathrm{Ec} / \mathrm{Io}=\mathrm{RSCP} / \mathrm{RSSI}$

- RSSI (Received Signal Strength Indicator) is measured with the associated channel bandwidth in the above equation.

- Filtering

- The results of the measurement is filtered before reporting. Filtering of measurements is considered a low pass filtering technique. For filtering the following equation is applied.

- $\quad F n=(1-a) F n-1+a^{*} M n$

- Definition of Variants :

- Fn: filtered measurement result;

- Fn-1: last filtered measurement result;

- Mn: latest Ec/Io or RSCP measurement result that is received from the physical layer;

- $\quad \mathrm{A}=1 / 2(\mathrm{k} / 2)$, $\mathrm{k}$ means the "Filter coefficient," that includes the Measurement of Control message and is decided by UTRAN.

- $\quad \mathrm{F} 0$ is initialized by M1.

- Reporting

- The period report triggers the handover

- Due to filtered measurement result 
- Event report is the triggered handover

- Due to the event

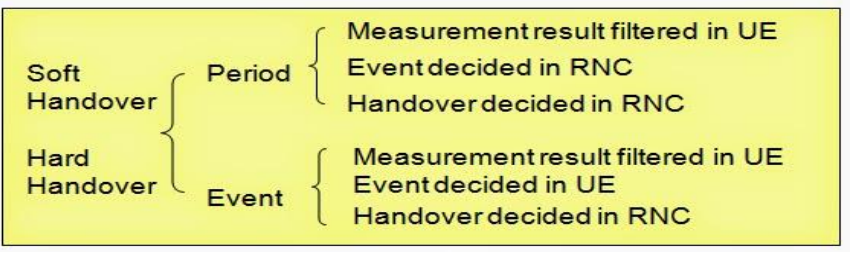

- Handover Algorithms

- All handover processes containing soft and hard handover, and other algorithms are applied to the quantity-reported event decision.

- Events are defined in 3GPP specifications

- Event of Intra-frequency is $1 \mathrm{~A}^{\sim} 1 \mathrm{~F}$

- Event of Inter-frequency is $2 \mathrm{~A}^{\sim} 2 \mathrm{~F}$

- Event of Inter-RAT is $3 \mathrm{~A}^{\sim} 3 \mathrm{D}$

- Note: RAT is "Radio Access Technology," e.g., UMTS\&GSM

\section{Concepts of Handover}

- Active Set:

- A group of cells which has radio links to a particular mobile station.

- User information is directed from all the cells.

- Monitored Set:

- A set of cells not in active set but which are tracked in compliance with the list of adjacent cells allocated by UTRAN.

- Detected Set:

- A set of cells neither in active set nor in monitor set. 


\begin{tabular}{c|l}
\hline Event & \multicolumn{1}{c}{ Description } \\
\hline 1A & $\begin{array}{l}\text { Quality of target cell improves, entering a } \\
\text { report range of relatively activating set quality }\end{array}$ \\
\hline 1B & $\begin{array}{l}\text { Quality of target cell decreases, depart from a } \\
\text { report range of relatively activating set quality }\end{array}$ \\
\hline 1C & $\begin{array}{l}\text { The quality of a non-activated set cell is better } \\
\text { than that of a certain activated set cell }\end{array}$ \\
\hline 1D & Best cell generates change \\
\hline 1E & $\begin{array}{l}\text { Quality of target cell improves, better than an } \\
\text { absolute threshold }\end{array}$ \\
\hline 1F & $\begin{array}{l}\text { Quality of target cell decreases, worse than } \\
\text { an absolute threshold }\end{array}$
\end{tabular}

Fig. 8. Soft Handover Event

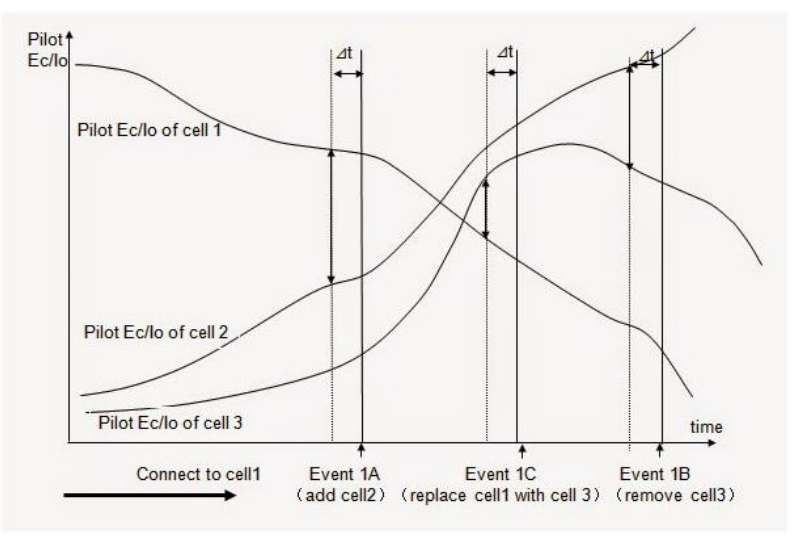

Fig. 9. An Example of SHO Procedure

\section{Simulation model}

Remember Fig's scenario of handing over. 11 In which the MN switches from the Global Mobile Communications System (GSM) network to WiMAX network domain with the velocity' v.' The distance between the two BSs is $\mathrm{D}=\mathrm{R} 1+\mathrm{R} 2 \mathrm{~L}$, where the $\mathrm{BS} 1$ and $\mathrm{BS} 2$ radii are $\mathrm{R} 1$ and $\mathrm{R} 2 . \mathrm{L}$ is Two BSs ' overlapping distance. The signal strength $\mathrm{MN}$ has received from $\mathrm{BSi}$ is

$$
\mathrm{Si}(\mathrm{k})=\mathrm{Pt}+\mathrm{Gt}-\mathrm{Lt}-\mathrm{PLi}(\mathrm{k})+\mathrm{Gr}-\mathrm{Lr}
$$

Where Pt is the transmitted signal strength from BS. Gt, Lt and Gr, Lr are considered as the antenna gains, transmitter and receiver loss respectively. PLi(k) represents the path loss component at Kth sample distance from BSi. The Okumura Hata propagation model is considered as the GSM network. The path loss equation is

Pli $(\mathrm{k})=69.55+26.16 \log \mathrm{fi}-13.82 \log \mathrm{hb}-\alpha(\mathrm{hm})+(44.9-6.55 \log \mathrm{hb}) \log \operatorname{di}(\mathrm{k})$ 
WiMAX network an extended version of Erceg model uses equation for calculating path loss in decibels and is given by

Pli $(k)=A+10 \gamma \log 10(\mathrm{di}(\mathrm{k}) / \mathrm{d} 0)+\mathrm{Zi}(\mathrm{k})+\mathrm{PLf}+\mathrm{PLhms}+\mathrm{PL} \theta \mathrm{ms}$
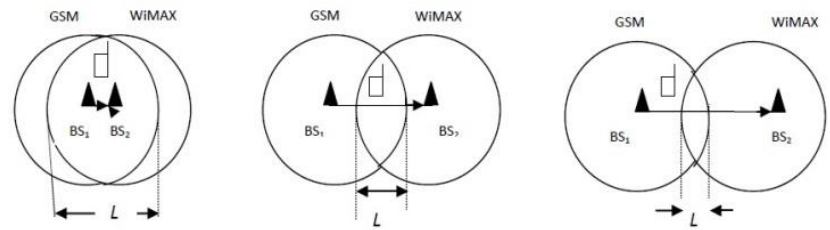

Fig. 10. Handover Scenario

Where $\mathrm{d}_{\mathrm{i}}(\mathrm{k})$ is considered as the distance between $\mathrm{BS}_{\mathrm{i}}$ and $\mathrm{MN}$ at $\mathrm{k}^{\text {th }}$ Sampling instant and $\mathrm{Z}(\mathrm{k})$ is the shadow fading component at $\mathrm{k}^{\text {th }}$ sampling instant, which is log-normally distributed and is described (in $\mathrm{dB}$ ) as the Gaussian distribution with a zero mean and standard deviation $\sigma_{\text {. }}$.

$$
Z_{i}(\mathrm{k})=\rho_{i} Z_{i}(k-1)+\sigma_{i} \sqrt{1-p i^{2}} \eta_{i}(0,1)
$$

Where $\rho$ i is correlation coefficient of $\{\mathrm{Zi}(\mathrm{k})\}$. $\eta \mathrm{i}(0,1)$ are standard random variables with a zero mean and variance as unity function. Parameter A represent the free space path loss and represented as

$$
\begin{aligned}
& \mathrm{A}=20 \log _{10} \frac{4 \pi d 0}{\gamma} \\
& \gamma \text { - path loss exponent and defined as } \\
& \gamma=\mathrm{a}-\mathrm{bhb}+\frac{\mathrm{c}}{\mathrm{hb}} \\
& \mathrm{PL}_{\mathrm{f}}=6 \log \frac{\mathrm{fi}}{1900} \\
& \mathrm{PL}_{\mathrm{hms}}=-20 \log \left(\frac{\mathrm{hm}}{2}\right) \text { for Suburban areas } \\
& \mathrm{PL}_{\mathrm{rms}}=0.64 \ln \left(\frac{\mathrm{a}}{360}\right)+0.54\left(\ln \left(\frac{\mathrm{a}}{360}\right)\right) 2
\end{aligned}
$$

Where fi is considered as carrier frequency, and bhb as base station antenna height in meters. The empirical constants are well defined for suburban areas in Erceg model and is given in Table 1. PLF, PL $\mathrm{L}_{\mathrm{mm}}, \mathrm{PL}_{\mathrm{mm}}$ are the correction factors that are corresponding to frequency $\mathrm{f}_{\mathrm{i}}, \mathrm{MN}$ height ${ }_{\mathrm{m}} \mathrm{HM}$, and $\mathrm{MN}$ antenna directivity q. $\mathrm{PL}_{\mathrm{mms}}$ is often referred as the antenna-gain reduction factor and helps in angular scattering reduction owing to the directivity of the antenna. $\alpha\left(\mathrm{h}_{\mathrm{m}}\right)$ is the antenna correction factor in an urban area expressed in $\mathrm{dB}$ and is given as 
Table 1. Parameters of Simulation

\begin{tabular}{|l|l|l|l|}
\hline $\mathrm{R}_{\mathrm{t}}=5000 \mathrm{~m}$ & GSM cell Radius & $\mathrm{L}_{\mathrm{t}}=3 \mathrm{~dB}$ & Loss of Transmitter antenna \\
\hline $\mathrm{R}_{2}=5000 \mathrm{~m}$ & WiMAX cell Radius & $\mathrm{G}_{\mathrm{r}}=0 \mathrm{~dB}$ & Gain of Receiver antenna \\
\hline $\mathrm{d}_{\mathrm{l}}=100 \mathrm{~m}$ & Correlation distance & $\mathrm{G}_{\mathrm{t}}=8 \mathrm{~dB}$ & Loss of Transmitter antenna \\
\hline $\mathrm{P}_{\mathrm{t}}=43 \mathrm{dBm}$ & Transmitter power & $\sigma_{\mathrm{i}}=8 \mathrm{~dB}$ & $\begin{array}{l}\text { Standard deviation of } \\
\text { shadowfading }\end{array}$ \\
\hline $\mathrm{V}=(1-25) \mathrm{m} / \mathrm{s}$ & MN Velocity & $\mathrm{h}_{\mathrm{b}}=50$ meter & Height of Base station antenna \\
\hline $\mathrm{q}=10$ & MN antenna directivity & $\mathrm{h}_{\mathrm{m}}=2$ meter & Height of Mobile station antenna \\
\hline$\rho_{\mathrm{i}}=0.35$ & Correlation coefficient & $\mathrm{f}_{\mathrm{l}}=900 \mathrm{MHz}$ & GSM Carrier Frequency \\
\hline $\mathrm{G}_{\mathrm{t}}=18 \mathrm{~dB}$ & $\begin{array}{l}\text { Gain of Transmitter } \\
\text { antenna }\end{array}$ & $\mathrm{f}_{2}=900 \mathrm{MHz}$ & WiMAX Carrier Frequency \\
\hline $\mathrm{T}_{\mathrm{s}}=10 \mathrm{~ms}$ & Sampling time & $\mathrm{S}_{\mathrm{th}}=-100 \mathrm{~dB}$ & Threshold of Signal Strength \\
\hline $\mathrm{a}=3.6$ & $\mathrm{~b}(\mathrm{~m})=0.005$ & $\left.\mathrm{c}^{-1}\right)=20$ & \\
\hline
\end{tabular}

\section{Conclusion}

I have offered a list of some methods that have been used in the field of mobile communication handover so far, and it is worth mentioning that Quality of Services (QoS) in mobile communication and is mostly knotted to success and how quickly the handover takes place. It is also well known that the soft computing-based algorithm performs better due to soft computing method's aptitude for gripping the uncertainty embedded in mobile wireless communication network. Consequently, selection of multiple and appropriate network parameters requires more seamless handover.

\section{References}

[1] Kai Niu, Weiling Wu. (2005): Mobile Communication principle, Beijing, Publishing house of the electronics industry.

[2] Jiang Xie, Weiyi Zhao. (2009): Inter-gateway Cross-layer Handoffs in Wireless Mesh Networks, IEEE proceedings "Globecom", pp. 1-6.

[3] Brahmjit S. (2005): Outage probability analysis in soft handover for $3 \mathrm{~g}$ wireless networks. $3 \mathrm{G}$ and Beyond, 6th IEEE International Conference on. Pp. 1-5

[4] S. Migaldi, L. Eastwood, V. Gupta, Qiaobing Xie. (2008): Mobility using IEEE 802.21 in a heterogeneous IEEE 802.16/802.11-based, IMT-advanced (4G) network. IEEE Wireless Communications, pp.26-34.

[5] Mhatre, V., Papagiannaki, K. (2006): Using smart triggers for improved user performance in 802.11 Wireless Networks, ACM Mobisys'06, pp. 246-259. 
[6] Golmie, N., Woon, S., Sekercioglu, Y. A, (2006): Effective link triggers to improve handover performance, IEEE PIMRC06, pp. 1-5.

[7] Brahmjit S., Shakti K., K Aggarwal, (2003): Handover Initiation Control Techniques in Mobile Cellular Systems, IETE Technical Review, vol. 20., pp. 13-21.

[8] Azita L. Y., Norsuzila Y., Mohd T. A., (2011): Handover Initiation Across Heterogeneous Access Networks for Next Generation Cellular Network, 2011 IEEE Symposium on Wireless Technology and Applications (ISWTA), Langkawi, Malaysia, pp. 9-12.

[9] D. Cypher, S. Yoo, N. Golmie, (2008): Predictive Link Trigger Mechanism for Seamless Handovers in Heterogeneous Wireless Networks, Wireless Communications, and Mobile Computing.

[10] Shucong J., Wenyu L., Xiaoyu D., Lin Z., Yu L., Jiaru L., (2012): “A Dynamic Hysteresis-adjusting Algorithm in LTE Self-Organization Networks," IEEE.

[11] Ronny Y. K., Inuk J., Xiangying Y., Chao-Ch. Ch., (2010): "Advanced Handover Schemes in IMT-Advanced Systems," IEEE Communications Magazine, pp.78-85.

[12] Kwan-Cheng Chen, J. Roberto De Marca, (2008): "Mobile WiMAX”, pp. 5-6.

[13] Choi, S., T. Kwon and G.H. Hwang, (2005): "Fast handover scheme for real-time downlink services in IEEE 802.16e BWA system.” In IEEE VTC, 3: 2028-2032.

[14] K. Kyamakya, Lee, D.H., and J.P. Umondi, "Fast Handover Algorithm for IEEE 802.16e Broadband Wireless System”.

[15] Zdenek BECVAR, Pavel MACH, Robert BESTAK, "Initialization of Handover Procedure in WiMAX Networks."

\section{Acknowledgements}

The author declare that they have no conflict of interest.

\section{Conflict of interest}

The author declare that they have no conflict of interest.

\section{About The License}

(C) 2020 The Authors. This work is licensed under a Creative Commons Attribution 4.0 International License which permits unrestricted use, provided the original author and source are credited. 